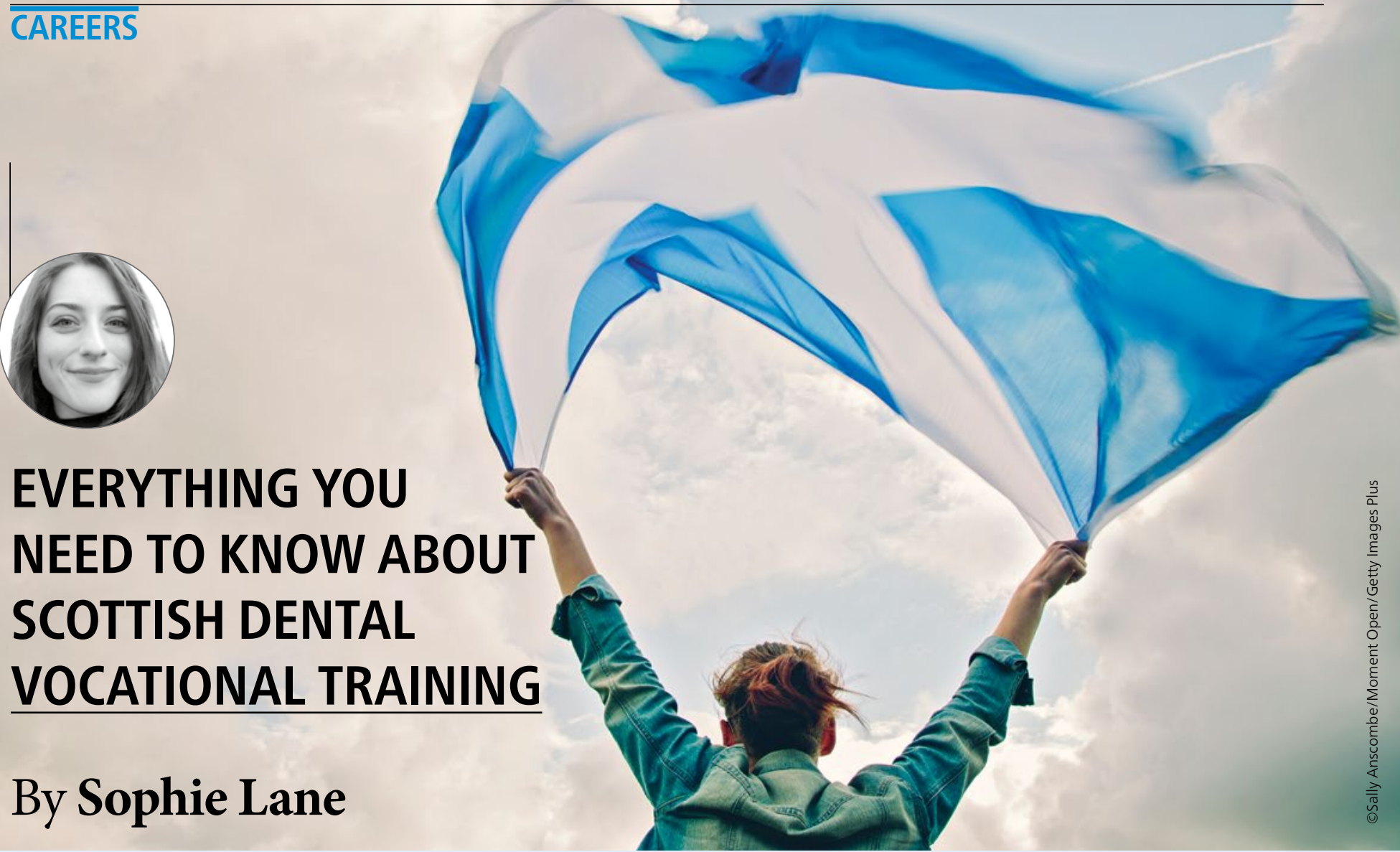

\section{What is DVT?}

DVT is the Scottish equivalent of Dental Foundation Training (DFT), undertaken in the year post-graduation. You are placed in a dental practice with a designated 'trainer' - an experienced dentist with an interest in teaching. Sometimes training duties are split between two dentists and they each become known as 'joint' trainers. Teaching styles vary, but for the most part trainers will be in a room close to yours, managing their own patients whilst having an 'open-door' policy to help you should you need it. Your trainer is also responsible for giving you weekly tutorials on various topics. Once a week during both DVT and DFT, you will have a 'study day' with other trainees in your area, where you develop and hone your clinical skills and learn more about dentistry as a profession.

\section{Is it the same as DFT?}

Though inevitably there are nuances between the two programmes, fundamentally, yes, DVT is the same as DFT. They both offer graduates an invaluable year of experience in a general dental practice, as well as a structured educational programme. Following both DVT and DFT, you can progress directly into Dental Core Training (Year 1).

The main difference is the application process. Where the DFT process ranks one thousand graduates in the UK based on a Situational Judgement Test and a standardised interview process, DVT applications are much more personal and old-fashioned. You meet the trainers before ranking and have some time to interrogate and impress each other. Your years of hard work at dental school and CV-building count for something, and you can make a more informed decision when preferencing your choices. Some people hate the interview process and preferred the anonymity of DFT's national recruitment. Others, like myself, really enjoyed the 'speeddating' style interviews; bombarding each trainer with questions, learning about their professional values and seeing if there was that all-important 'spark'.

NHS Scotland and NHS England also have different dental contracts. Units of Dental Activity (UDAs) will be well-known to anyone even slightly familiar with NHS dentistry in England, however in Scotland, there are no UDAs or banding for payments. Instead, there are fees for every possible item of treatment which are detailed in the Scottish Dental Remuneration. Whether UDAs are good or bad is a matter of opinion, and so shall not be touched upon here, but something to bear in mind if you plan on becoming an associate following DVT/DFT. You may wish to use your training year to get to grips with the system you'll be under as an associate while you're salaried and under less financial pressure to perform. Otherwise, if you intend on finding NHS work in England following DVT in Scotland, or in Scotland following DFT in England, for example, you may have to play catch-up. However, in the aftermath of COVID-19, we will likely see the reformation of NHS contracts entirely, so this shouldn't be a deciding factor.

As far as the administrative side of things pre-training, you will need to register with the GDC still, but you will not need to complete a National Performers List application as you would pre-DFT. There are other small differences in paperwork, but all of this will be given to you in a welcome package once you have received a job offer and is not something to worry about.

\section{How to apply \\ Stage 1}

The first stage of the application process is in late September, where you register your interest in DVT via Oriel, the same way you do for DFT. It is a very simple form to fill out, with the submission of a few supporting documents e.g. proof of address - if memory serves, the application took me less than 15 minutes. If you have even a mild inclination to train in Scotland, you should apply at this time, as you can retract your application later with no consequence, but once the October deadline passes, your chance has gone. You can now sit back and relax until May, when the second stage begins.

\section{Stage 2: Visitation period}

On a specific date in May, information about each trainer will be 'released' onto an online portal, which you will be emailed a link to. The portal groups practices based on regions 
in Scotland - East, North, North East, South East and West. You can view these as a list, or spots on a map. These regions have no real significance other than to narrow down your practice search to location e.g. the South East region if you wish to train in Edinburgh. Your study days will be with other trainees in the same regions as you. However, some regions have more than one 'study' group based on the size of the region, meaning two trainees in Edinburgh could be on different study days, for example.

\section{Preferencing}

Once you have had your interviews, you will need to rank seven trainers in order of preference. There is no minimum number of trainers to rank, but seven is the maximum and I would advise you to use all of these lest you end up jobless. The trainers also submit seven preferences, and a matching algorithm does the rest.

Side note: It is common for trainers to email you to see if there is mutual interest, so neither of you waste a spot on your list. However, it is against the rules to tell each other the exact

\section{'Even if nothing comes of it, you'll have gained loads of interview experience for future associate jobs!'} position they hold on the list, so be respectful of the process and wary of any trainer who tells you "you are my first choice!" It is not only unethical to do so, but merely a strategy, so don't be fooled.

The algorithm favours the trainer, running through all trainers' first

Each trainer will have a 'profile', where you will find their contact details, practice address, and brief 'get to know me' sections written by the trainers themselves. You will use this information to decide which practices to apply to. Some trainers may also include hyperlinks to video tours of their practices, and (even more rarely) video testimonials from previous VTs. These are incredibly useful to gauge what a practice is like without having visited, and it says a lot about trainers who put in the extra effort to make these.

You will have access to the portal for a two-week period; in these two weeks, you are expected to contact trainers with your $\mathrm{CV}$ and a cover letter, arrange interviews and subsequently rank your trainer preferences. In 2020, this was all done online due to COVID-19, and interviews were conducted via video call. In previous years, you had the opportunity to visit the practices and interviews were done face-to-face. What the visitation period will look like next year is uncertain. Personally, I found the Zoom interviews extremely convenient, so don't be disheartened if they opt for this in future years. I would've spent a fortune travelling 6 hours to Scotland and staying in an Airbnb for two weeks, and I felt video tours of the practices were a perfectly adequate substitute for the real thing. However, undoubtedly others would have preferred in-person visitation. have to complete a preference list. These posts are rare though (if memory serves, there were none in the South East region this year), so I'd advise you to come to terms with being subject to the algorithm.

If you have not been matched to a trainer, you will enter into 'clearing period'. It is your job to then contact the remaining trainers, who will then offer their post directly to the person they wish to fill it. Clearing runs for as long as it takes for all posts to be filled.

\section{Summary}

DVT posts are extremely competitive, especially in sought-after locations such as Edinburgh or Glasgow. Though figures will vary between trainers, regions, and years, to give you a rough idea of the competition, over four of my interviewers told me they'd received $\sim 65$ applications and were interviewing $\sim 15$ applicants. With these odds, a lot of students find themselves entering the clearing process, which can be taxing and demoralising.

Competition aside, back-to-back interviews are exhausting, even over the web. When the trainers' information is released onto the portal, expect to spend a day glued to your computer writing cover letter after cover letter. It is enough to make you want to abandon your DVT application altogether - but stick with it. If you're prepared with a template cover letter and interview questions, you can streamline the process and minimise the feeling of overwhelm. It is confidenceinspiring when an interview goes well, or a trainer expresses interest in you, unlike DFT where you are reduced to just a number. Even if nothing comes of it, you'll have gained loads of interview experience for future associate jobs!

I would thoroughly recommend applying for DVT to anyone who wishes to live and work in Scotland. I know it feels like a daunting process, particularly because English universities provide little to no information on it, but trust me when I say it is surprisingly easy to navigate. Don't let the competition deter you. There will be competition wherever you go, and nothing worth having comes easy. Back yourself - you've made it this far, and any trainer would be lucky to have you. All your efforts will be totally worth it for the feeling you get when you are assigned your dream post. Good luck!

Sophie Lane commence (usually they start on 1 August, but pushed back this year due to COVID-19) released (in 2020, this released was within minutes of DFT ranking results)

15 June 2020 - Clearing opened for direct appointments

\section{Sophie Lane}

